University of Wollongong

Research Online

Faculty of Engineering and Information

Faculty of Engineering and Information

Sciences - Papers: Part A

Sciences

$1-1-2014$

\title{
The effects of feed solution temperature on pore size and trace organic contaminant rejection by the nanofiltration membrane NF270
}

\author{
Hai Quang Dang \\ University of Wollongong, hdq686@uowmail.edu.au \\ William E. Price \\ University of Wollongong, wprice@uow.edu.au \\ Long Duc Nghiem \\ University of Wollongong, longn@uow.edu.au
}

Follow this and additional works at: https://ro.uow.edu.au/eispapers

Part of the Engineering Commons, and the Science and Technology Studies Commons

Research Online is the open access institutional repository for the University of Wollongong. For further information contact the UOW Library: research-pubs@uow.edu.au 


\title{
The effects of feed solution temperature on pore size and trace organic contaminant rejection by the nanofiltration membrane NF270
}

\begin{abstract}
This study investigated the effect of feed temperature on membrane pore size and the rejection of trace organic contaminants (TrOCs) by the nanofiltration (NF) membrane NF270. Filtration experiments were conducted using a cross flow membrane system at 20,30 and $40 \mathrm{C}$. The membrane pore radius was estimated using the pore hindrance transport model at each temperature and the rejection data of three reference organic solutes (i.e. erythritol, xylose and glucose) experimentally obtained in this study. The results suggest that the pore size of an NF membrane is dependent on the feed solution temperature. An increase in the feed temperature from 20 to $40 \mathrm{C}$ led to an increase in the effective pore radius from 0.39 to $0.44 \mathrm{~nm}$. Consequently, the increase in the feed temperature also caused a considerable drop in the rejection of all TrOCs investigated in this study. The decrease in rejection observed here could be attributed to not only the increase in the solute diffusivity but also the enlargement of the membrane pore size. As the feed temperature increased, the decrease in rejection of neutral TrOCs was more severe than that of negatively charged compounds. This is because in addition to size exclusion (or steric hindrance) the rejection of negatively charged TrOCs is also governed by electrostatic interaction given that the membrane surface is also negatively charged.
\end{abstract}

\section{Keywords}

trace, organic, rejection, nanofiltration, contaminant, membrane, pore, nf270, feed, effects, temperature, solution, size

\section{Disciplines}

Engineering | Science and Technology Studies

\section{Publication Details}

Dang, H. Quang., Price, W. E. \& Nghiem, L. Duc. (2014). The effects of feed solution temperature on pore size and trace organic contaminant rejection by the nanofiltration membrane NF270. Separation and Purification Technology, 125 (April), 43-51. 


\title{
The effects of feed solution temperature on pore size and trace organic contaminant rejection by the nanofiltration membrane NF270
}

\author{
Hai Quang Dang ${ }^{a}$, William E. Price ${ }^{\mathrm{a}, *}$, Long Duc Nghiem ${ }^{\mathrm{b}}$ \\ a Strategic Water Infrastructure Laboratory, School of Chemistry, University of Wollongong, \\ Wollongong, NSW, 2500, Australia \\ b Strategic Water Infrastructure Laboratory, School of Civil, Mining and Environmental \\ Engineering, University of Wollongong, NSW, 2500, Australia \\ * Corresponding author. \\ E-mail address: wprice@uow.edu.au; Tel: +61 242218089;
}

\begin{abstract}
A B S T R A C T
This study investigated the effect of feed temperature on membrane pore size and the rejection of trace organic contaminants (TrOCs) by the nanofiltration (NF) membrane NF270. Filtration experiments were conducted using a cross flow membrane system at 20,30 and $40{ }^{\circ} \mathrm{C}$. The membrane pore radius was estimated using the pore hindrance transport model at each temperature and the rejection data of three reference organic solutes (i.e. erythritol, xylose and glucose) experimentally obtained in this study. The results suggest that the pore size of an NF membrane is dependent on the feed solution temperature. An increase in the feed temperature from 20 to $40{ }^{\circ} \mathrm{C}$ led to an increase in the effective pore radius from 0.39 to $0.44 \mathrm{~nm}$. Consequently, the increase in the feed temperature also caused a considerable drop in the rejection of all TrOCs investigated in this study. The decrease in rejection observed here could be attributed to not only to the increase in the solute diffusivity but also the enlargement of the membrane pore size. As the feed temperature increased, the decrease in rejection of neutral TrOCs was more severe than that of negatively charged compounds. This is because in addition to size exclusion (or steric hindrance) the rejection of negatively charged TrOCs is also governed by electrostatic interaction given that the membrane surface is also negatively charged.
\end{abstract}

Keywords: Nanofiltration; Trace organic contaminants (TrOCs); Pore radius; Rejection.

\section{Introduction}

Over the last few decades, there has been much research on the rejection of trace organic contaminants (TrOCs) such as endocrine disrupting chemicals, pharmaceuticals and pesticides by 
nanofiltration (NF) membranes [1-7]. However, despite the fact that temperature is an important factor governing mass transfer in membrane separation processes, most of previous studies were performed at an arbitrary temperature and the impact on temperature on TrOC rejection has not been systematically investigated. In fact, several previous studies have demonstrated that the temperature has a significant impact on NF membrane performance. According to Goosen et al. [8], polymeric membrane is sensitive to changes in the feed temperature. They reported an increase of up to $60 \%$ in the permeate flux when the feed temperature was increased from 20 to $40^{\circ} \mathrm{C}$. A linear relation between temperature and water flux by NF performances has been reported in the temperature range from 10 to $30{ }^{\circ} \mathrm{C}$ [9] and 20 to $70{ }^{\circ} \mathrm{C}$ [10]. It was explained that the flux increased with the temperature was attributed to the thermal expansion of the membrane material [9-10]. In a study on the effect of temperature on the permeation characteristics of NF membranes, Sharma et al. [11] suggested that with increasing temperature, the average pore size increased and the pore density decreased because of the thermal expansion of the polymer constituting the active layer of thin-film composite membranes. These could be the cause of the reduction in rejection of organic solutes by NF membranes with increasing temperature. Therefore, a comprehensive understanding of the rejection mechanisms and mathematical models of TrOCs by NF processes under different temperature conditions is very important for the prediction of solute rejection, optimization of treatment processes, and development and application of new methodologies.

The membrane pore size and molecular dimensions of organic solutes are important factors which can affect their rejection during NF filtration $[3,12]$. Several mathematical models, applied so far to estimate the membrane pore size, were based on the uncharged solute transport across the membranes under different permeate flux conditions. Wang et al. [13] applied the steric-hindrance pore (SHP) model to estimate the pore radius of NF membrane (G-20) from the permeation experiments of different uncharged solutes (such as glucose, saccharose, raffinose and $\alpha$ cyclodextrin) at $25{ }^{\circ} \mathrm{C}$ and demonstrated that the rejection was influenced strongly by molecular weight, Stokes radius and diffusion coefficient of these solutes. In a other study, Bowen and Welfoot [14] estimated the NF membrane pore radius (Desal-DK) based on the Donnan-steric pore model (DSPM) using two uncharged solutes including glycerol and glucose at $25^{\circ} \mathrm{C}$. Their findings showed a difference in the pore radius for both tested solutes, owing to their different physicochemical properties (such as Stokes radius and diffusion coefficient). López-Muňozet et al. [15] successfully applied the SHP model in order to calculate the pore radius of NF membranes (NF270 and NF90) using three uncharged solutes (ribose, glucose and sucrose) at the same temperature. They also elucidated the relationship between the membrane pore size characterisations and rejection efficiency of phenolic TrOCs and concluded that rejection of these compounds by the NF90 membrane was higher than for the NF270 membrane, because of its 
smaller pore size [15]. Despite a large volume of research on the effects of the membrane pore size on the rejection of trace organic solutes by NF membranes, to date, there have yet been any studies on the effect of temperature on membrane pore size and rejection of TrOCs by NF membranes. Additionally, the combined influence of the membrane pore size and diffusion of TrOCs across the membrane on their rejection efficiency is still poorly understood.

The objectives of the current work were to study and assess the effects of the feed temperature on pore radius and TrOC rejection by the NF process. The pore-hindrance transport model was used to determine the average pore radius of the membrane at 20,30 , and $40{ }^{\circ} \mathrm{C}$ using reference neutral organic solutes. Subsequently, the influence of the membrane pore size and diffusion behaviour of the target TrOCs on their rejection at different temperatures were examined and discussed. The results enable the evaluation of the role of feed temperature on TrOC rejection by the NF process.

\section{Experimental}

\subsection{Nanofiltration membrane}

The NF270 membrane (Dow-Filmtec, Minneapolis, MN) was selected for this study. According to the manufacturer, it is a thin-film composite polyamide membrane that is widely used for water and wastewater treatment application. This is a loose NF membrane with a relatively high permeability (of approximately $11 \mathrm{~L} / \mathrm{bar}^{2} \mathrm{~h}$ ). At $\mathrm{pH} 4$ and above, this membrane is negatively charged [16]. The flat sheet membrane samples were stored dry before use.

\subsection{Theoretical background and calculation method}

In order to determine the pore size of the membrane and the effect of temperature, three uncharged reference solutes were used. In the pore-hindrance model, transport of uncharged solutes through a membrane are governed by two important mechanisms of solute transport through the NF membrane, namely diffusion, as a result of concentration gradients and convection caused by the pressure difference across the membrane $[13,17]$. Their transport equation is thus given as the sum of the diffusive and the convective terms as follows $[12,18]$ :

$$
\begin{aligned}
& J_{\mathrm{S}}=\mathrm{K}_{\mathrm{c}} \mathrm{CJ}_{\mathrm{v}}-\mathrm{D}_{\mathrm{p}} \frac{\mathrm{dC}}{\mathrm{dx}} \\
& \mathrm{J}_{\mathrm{s}}=\mathrm{J}_{\mathrm{V}} \mathrm{C}_{\mathrm{p}}
\end{aligned}
$$

Where $J_{s}$ and $J_{v}$ are the solute and solution fluxes, respectively, $K_{c}$ is the convective hindrance coefficient, $\mathrm{C}$ is the solute concentration in the membrane pore, $\mathrm{D}_{\mathrm{p}}$ is the hindered solute diffusivity in the membrane pores, $D_{p}=K_{d} D$ with $D$ is the bulk diffusivity and $K_{d}$ is the diffusive hindrance 
coefficient, $\mathrm{x}$ is the axial position within the membrane pore and $\mathrm{C}_{\mathrm{p}}$ is the solute concentration of the bulk permeate.

The hindrance factors $\left(\mathrm{K}_{\mathrm{c}}\right.$ and $\left.\mathrm{K}_{\mathrm{d}}\right)$, are functions of the ratio of the solute radius to the pore $\operatorname{radius}(\lambda)$ :

$$
\lambda=\frac{\mathrm{r}_{\mathrm{s}}}{\mathrm{r}_{\mathrm{p}}}
$$

In the range of $0<\lambda<0.8$, these factors can be calculated by following equations $[12,18]$ :

$$
\begin{aligned}
& \mathrm{K}_{\mathrm{d}}=1-2.3 \lambda+1.154 \lambda^{2}+0.224 \lambda^{3} \\
& \mathrm{~K}_{\mathrm{c}}=(2-\Phi)\left(1+0.054 \lambda-0.988 \lambda^{2}+0.441 \lambda^{3}\right)
\end{aligned}
$$

The steric partition factor $(\Phi)$ is defined as the ratio of the solute-accessible area to the pore area and is expressed as follows:

$$
\Phi=(1-\lambda)^{2}
$$

Because the diffusion coefficient (D) is associated with solute radius and the mass transfer coefficient, it is an important parameter that influences solute transport across the membrane. Diffusion coefficient of TrOCs in water can be calculated by Wilke and Chang equation [19]. This equation can give satisfactory predictions for the diffusivity of trace organicsolutesin water.

$$
\mathrm{D}=\frac{1.173 \times 10^{-13}(\phi \mathrm{M})^{0.5} \mathrm{~T}}{\mu \mathrm{V}_{\mathrm{m}}^{0.6}}
$$

Where $\phi$ is an association factor for the solvent ( $\phi=2.6$ for water), M is molecular mass of solvent ( $\mathrm{M}=18 \mathrm{~g} /$ mole for water), $\mu$ is the viscosity of solvent, $\mathrm{T}$ is the absolute temperature and $\mathrm{V}_{\mathrm{m}}$ is molar volume of the solute at its boiling point. $\mathrm{V}_{\mathrm{m}}$ can be estimated from the group contributions of structural contributions to molar volumes [19].

The solute radius $\left(\mathrm{r}_{\mathrm{s}}\right)$ used in Eq. (3) is the effective solute radius in the pore, commonly estimated by Stokes-Einstein equation [3, 20].

$$
\mathrm{r}_{\mathrm{s}}=\frac{\mathrm{kT}}{6 \pi \mu \mathrm{D}}
$$

Where $\mathrm{k}$ is Boltzman's constant, $\mathrm{T}$ is the absolute temperature, and $\mu$ is the viscosity of the solvent which is water in this case. As can be seen from Eqs. (7) and (8), the solute size is independent of the solution temperature. Thus, at a given permeate flux, changes in the solution temperature are related only to the membrane pore size and the diffusion coefficient of the solute.

The previous assumption also allows to introduce the Hagen-Poiseuille equation definition of pore solvent velocity in the Peclet number definition (Pe), thus it can be considered a model parameter in rejection of the solutes by the membranes [21].

$$
\mathrm{Pe}=\frac{\mathrm{K}_{\mathrm{c}} \mathrm{J}_{\mathrm{v}} \Delta \mathrm{x}}{\mathrm{D}_{\mathrm{p}}}
$$


Where $\Delta \mathrm{x}$ is the length of the pore.

The concentrations of the solute at the inlet and outlet sides of the pore $\left(C_{i}\right.$ and $C_{0}$, respectively) are expressed in terms of the steric partition factor and the permeate and membrane surface solute concentrations $\left(\mathrm{C}_{\mathrm{p}}\right.$ and $\left.\mathrm{C}_{\mathrm{m}}\right)$ as follows $[18,22]$ :

$$
\begin{aligned}
& \mathrm{C}_{\mathrm{i}}=\Phi \mathrm{C}_{\mathrm{m}} \\
& \mathrm{C}_{\mathrm{o}}=\Phi \mathrm{C}_{\mathrm{p}}
\end{aligned}
$$

In order to obtain an expression for rejection of the solute, Eq. (1) is integrated across the membrane with the solute concentrations in the membrane at the upper $(\mathrm{x}=0)$ and lower $(\mathrm{x}=\Delta \mathrm{x})$ surfaces expressed in terms of $\mathrm{C}_{\mathrm{m}}$ and $\mathrm{C}_{\mathrm{p}}$ using the equilibrium partition coefficient, $\Phi . \mathrm{C}_{\mathrm{x}=0}=\Phi \mathrm{C}_{\mathrm{m}}$ and $\mathrm{C}_{\mathrm{x}=\Delta \mathrm{x}}=\Phi \mathrm{C}_{\mathrm{p}}$. In terms of real rejection $\left(\mathrm{R}_{\text {real }}\right)$ of the solute, the above Eq. (1) can be integrated through the membrane, then substituting $C_{m}$ and $C_{p}$ from Eqs. (10) and (11), and introducing the Peclet number from Eq. (9), the Eq. (1) becomes:

$$
\mathrm{R}_{\text {real }}=1-\frac{\mathrm{C}_{\mathrm{p}}}{\mathrm{C}_{\mathrm{m}}}=1-\frac{\Phi \mathrm{K}_{\mathrm{c}}}{1-\left[1-\Phi \mathrm{K}_{\mathrm{c}}\right] \exp (-\mathrm{Pe})}
$$

Where $\Phi$ is steric partition factor. In the NF process, solute rejection results in a concentration polarization at the membrane and bulk solution interface. Therefore, relationship between $C_{m}$ and $\mathrm{C}_{\mathrm{p}}$ in concentration polarization is expressed in the Film Theory Model $[11,23]$ as:

$$
\frac{\mathrm{C}_{\mathrm{m}}-\mathrm{C}_{\mathrm{p}}}{\mathrm{C}_{\mathrm{b}}-\mathrm{C}_{\mathrm{p}}}=\exp \left(\frac{\mathrm{J}_{\mathrm{v}}}{\mathrm{k}_{\mathrm{f}}}\right)
$$

Where $C_{b}$ is the bulk concentration of the solute in the feed and $k_{f}$ is mass transfer coefficient.

Using the rejection fractions instead of concentrations, the relationship between observed rejection $\left(R_{\mathrm{obs}}\right)$ and real rejection $\left(\mathrm{R}_{\text {real }}\right)$ can be presented as follows:

$$
\ln \frac{1-\mathrm{R}_{\text {real }}}{\mathrm{R}_{\text {real }}}=\ln \frac{1-\mathrm{R}_{\text {obs }}}{\mathrm{R}_{\text {obs }}}-\frac{\mathrm{J}_{\mathrm{V}}}{\mathrm{kf}_{\mathrm{f}}}
$$

Where $\mathrm{R}_{\mathrm{obs}}$ is observed rejection, which is defined as:

$$
\mathrm{R}_{\text {obs }}=1-\frac{\mathrm{C}_{\mathrm{p}}}{\mathrm{C}_{\mathrm{b}}}
$$

$\mathrm{J}_{\mathrm{v}}$ and $\mathrm{R}_{\mathrm{obs}}$ can be experimentally measured. For a cross flow membrane filtration system, the mass transfer coefficient $\left(\mathrm{k}_{\mathrm{f}}\right)$ can be calculated by [24]:

$$
\mathrm{Sh}=\frac{\mathrm{k}_{\mathrm{f}} \mathrm{d}_{\mathrm{h}}}{\mathrm{D}}=0.065 \mathrm{Re}^{0.875} \mathrm{Sc}^{0.25}
$$

Where Sh is Sherwood number, Re is Reynolds number $\left(\operatorname{Re}=d_{h} \cdot \mathrm{u} / \mathrm{v}\right)$, where $d_{h}$ is hydraulic diameter, $\mathrm{u}$ is feed velocity and $\mathrm{v}$ is kinematic viscosity, and $\mathrm{Sc}$ is $\mathrm{Schmidt}$ number $(\mathrm{Sc}=\mathrm{v} / \mathrm{D})$. 


\section{3. $\mathrm{TrOCs}$}

Twelve TrOCs were selected to represent the major classes of phytoestrogens, pharmaceuticals and pesticides. Physiochemical properties of these compounds are summarised in Table 1. Most these compounds are hydrophilic properties $(\log \mathrm{D}<3)$, with amitriptyline and linuron being the only two exceptions. All compounds were of analytical grade and were purchased from SigmaAldrich (Sydney, Australia). Two stock solutions, one with the two phytoestrogens and another with the 10 other compounds were prepared at a concentration of $100 \mu \mathrm{g} / \mathrm{mL}$ in pure methanol. A working solution of these TrOCs was prepared at a concentration of $25 \mu \mathrm{g} / \mathrm{mL}$ for the two phytoestrogens and $50 \mu \mathrm{g} / \mathrm{mL}$ for the 10 other compounds in pure methanol from the two stock solutions. All these solutions were stored in a dark freezer at $-18^{\circ} \mathrm{C}$ prior to use.

Analytical grade erythritol, xylose and glucose (Sigma-Aldrich, Saint Louis, MO), were chosen as reference organic compounds to estimate the average pore radius of the NF270 membrane. They have low molecular weight and are uncharged. Therefore, the interaction between these compounds with the membrane is very weak.

In order to prepare the background electrolyte solution and adjust the solution $\mathrm{pH}$ for the experiments, $\mathrm{NaCl}, \mathrm{CaCl}_{2}, \mathrm{NaHCO}_{3}, \mathrm{NaOH}$, and $\mathrm{HCl}$ were used in this study. They were analytical grade chemicals and were supplied by Sigma-Aldrich (Castle Hill, Australia). Acetonitrile and methanol, both HPLC grade, were supplied by Crown Scientific (Sydney, Australia). Formic acid was purchased from Sigma-Aldrich (Sydney, Australia). Milli-Q water (Millipore, Billerica, MA, USA) was used for the preparation of feed solution.

\section{[Table 1]}

\subsection{Experimental protocol}

A laboratory scale cross flow NF/RO system consisted of a stainless steel NF/RO membrane cell with an effective surface area of $40 \mathrm{~cm}^{2}$ and channel height of $2 \mathrm{~mm}$, a stainless steel feed reservoir, and a high pressure pump (Hydra-Cell, Wanner Engineering Inc., Minneapolis, MN) was used. The temperature of the feed solution was controlled by a chiller/heater (Neslab RTE 7, Thermo Scientific Inc., Waltham, MA, USA) equipped with a stainless steel heat exchanger coil which was submerged directly into the feed reservoir. A digital flow meter (Optiflow 1000, Agilent Technologies, Palo Alto, CA) connected to a PC was utilized to measure permeate flow, and the cross flow was monitored with a rotameter.

The rejection of TrOCs was evaluated at 20,30 , and $40{ }^{\circ} \mathrm{C}$ in a background electrolyte solution containing $10 \mathrm{mM}$ of $\mathrm{NaCl}, 1 \mathrm{mM}$ of $\mathrm{CaCl}_{2}$, and $1 \mathrm{mM}$ of $\mathrm{NaHCO}_{3}(\mathrm{pH}$ 8). Prior to each experiment, the NF270 membrane samples were gently washed with copious Milli-Q water to remove any preservatives. They were then compacted using Milli-Q water at 1,000 $\mathrm{kPa}$ for at least 
one hour until a stable permeate flux had been obtained. The background electrolyte solution was then introduced to the feed reservoir, and made up to the total feed volume of 5 litres. During the experiment, the cross flow velocity and permeate flux were kept constant at $30.4 \mathrm{~cm} / \mathrm{s}$ and 42 $\mathrm{L} / \mathrm{m}^{2} \mathrm{~h}$, respectively. The feed temperature of experimental solution was controlled by a chiller/heater. The permeate and retentate flows were recirculated to the feed reservoir. A mixture of 12 target TrOCs was then added to the feed reservoir to obtain a concentration of $100 \mu \mathrm{g} / \mathrm{L} \mathrm{of}$ each of the other compounds and $50 \mu \mathrm{g} / \mathrm{L}$ of each of the two phytoestrogens (i.e. formononetin and genistein). The feed solution $\mathrm{pH}$ was kept constant during the experiments by periodically adding a small amount of $1 \mathrm{M}$ of $\mathrm{NaOH}$ or $1 \mathrm{M} \mathrm{HCl}$. Approximately $1 \mathrm{~mL}$ of feed and permeate samples were taken at specified time intervals for TrOC analysis.

To determine the membrane pore size, the membrane samples were initially compacted using Milli-Q water at 1,800 kPa for at least one hour. Subsequently, 5 litres of Milli-Q water was added to the feed reservoir. The cross flow velocity was kept constant at $30.4 \mathrm{~cm} / \mathrm{s}$. The feed temperature was adjusted to 20,30 , or $40^{\circ} \mathrm{C}$. The initial permeate flux was set at $10 \mu \mathrm{m} / \mathrm{s}$. A reference organic solute (erythritol, xylose or glucose) was added to the feed reservoir to obtain a concentration of 50 $\mathrm{mg} / \mathrm{L}$. The permeate flux was then incrementally increased from 10 to $20,30,40,50$, and $60 \mu \mathrm{m} / \mathrm{s}$, respectively. At each permeate flux set point, the system was operated for 1 hour before $20 \mathrm{~mL}$ of feed and permeate samples were taken for total organic carbon (TOC) analysis.

\subsection{Analytical methods}

Concentrations of the TrOCs in feed and permeate samples were determined using a Liquid Chromatography (LC) Mass Spectrometry (MS) system (LCMS-2020,Shimadzu, Japan). The LCMS system comprised of an autosampler (SIL-20A HT), pump (LC-20AD x 2 units), column oven (CTO-20A) equipped with a C18 column (Kinetex $2.6 \mu \mathrm{m}$ XB-C18 $100 \mathrm{~A}(100 \times 3.0 \mathrm{~mm})$ ), and a MS detector (LCMS-2020). A binary gradient consisting of $0.1 \%$ formic acid in Milli-Q water as solvent $\mathrm{A}$ and acetonitrile as solvent $\mathrm{B}$ at a flow rate of $0.5 \mathrm{~mL} / \mathrm{min}$ was used. A sample injection volume of $20 \mu \mathrm{L}$ was also used. The column temperature was set at $28{ }^{\circ} \mathrm{C}$. Analyte detection was performed by single ion monitoring MS analysis using negative electrospray ionization (ESI) for four of the organic compounds, namely diclofenac, formononetin, genistein and pentachlorophenol, and positive ESI for the other compounds. High purity nitrogen was used as the carrier gas for the ESI. Other interface parameters for the LC-MS system were as follows: interface temperature: 350 ${ }^{\circ} \mathrm{C}$, desolvation line temperature: $250{ }^{\circ} \mathrm{C}$, heat block temperature: $200{ }^{\circ} \mathrm{C}$ and nebulizing gas flow and drying gas flow rate were 1.5 and $5 \mathrm{~L} / \mathrm{min}$, respectively. This method was developed from previous studies [25-26]. Calibration standards were prepared in a background electrolyte solution containing $10 \mathrm{mM}$ of $\mathrm{NaCl}, 1 \mathrm{mM}$ of $\mathrm{CaCl}_{2}$, and $1 \mathrm{mM}$ of $\mathrm{NaHCO}_{3}$ at $\mathrm{pH}$. For the range of 
experimental concentrations used $(0,10,25,50,100$ and $200 \mu \mathrm{g} / \mathrm{L})$, all calibrations were linear with coefficients of determination $\left(\mathrm{R}^{2}\right)$ at least 0.99 .

The feed and permeate concentrations of the reference organic solutes include erythritol, xylose and glucose were determined by a TOC analyser (Shimadzu TOC-V CSH, Japan). TOC analysis was conducted in a non-purgeable organic carbon mode. The samples were sparged with ultra purity air (zero grade) to remove inorganic carbon and then injected into the total carbon (TC) port. The oven in the TC detector was set at $680{ }^{\circ} \mathrm{C}$ where non-purgeable organic carbon compounds were combusted and converted to $\mathrm{CO}_{2}$. The $\mathrm{CO}_{2}$ produced was then measured directly by a nondispersive infrared detector for carbon. Peak area on the recorder was directly related to the TC in the sample. The concentration of TOC in the feed and permeate samples were then calculated from the calibration curve.

\section{Results and discussion}

\subsection{Effect of temperature on the NF270 membrane pore radius}

The model parameters including the Stokes radius, diffusion coefficient and the mass transfer coefficient of the solutes at different temperatures were determined and summarised in Table 2. The observed rejection of reference organic solutes as a function of the permeate flux at feed temperature of 20,30 , and $40{ }^{\circ} \mathrm{C}$ were experimentally obtained and used to calculate the real rejection values using Eq. (14) and the mass transfer coefficients from Table 2. The pore hindrance transport model described in Eq. (12) was then applied to determine the values of $\Phi \mathrm{K}_{\mathrm{c}}$ using an optimization procedure (Solver, Microsoft Excel) to minimize the error between experimental and modelling values. The real rejection each reference organic solute as a function of permeate flux is presented in Fig. 1. According to Eqs. (5) and (6), $\Phi \mathrm{K}_{\mathrm{c}}$ is a function of the ratio of the solute radius to the pore radius $(\lambda)$, thus $\lambda$ can be obtained for each given reference organic solute and at each temperature value. The membrane average pore radius was calculated from $\lambda$ and radius $r_{s}$ of the reference organic solute (Table 3).

\section{[Figure 1]}

\section{[Table 2]}

\section{[Table 3]}

At each temperature, the obtained membrane pore radius was consistent for all three reference organic solutes. The membrane average pore radius increased from 0.39 to $0.44 \mathrm{~nm}$ as the feed temperature increased from 20 to $40{ }^{\circ} \mathrm{C}$ (Table 3). This enlargement of the membrane pore size is in agreement with results previously reported in the literature [11,27-28] and could be due to the 
thermal expansion of the polyamide skin layer. Tsuru et al. [29] and Sharma and Chellam [28] demonstrated that pore structures of the NF membranes such as pore diameter, thickness, and porosity could be altered with the increase of temperature because of thermal expansion. Sharma et al. [11] investigated the temperature dependence of several uncharged solutes (e.g. ethanol, ethylene glycol, dextrose, sucrose, xylose, glycerol and raffinose) using two different polyamide NF membranes (TFC-S and DL). After analysing the rejection dependence on the permeate flux of the solutes at different temperatures $\left(5-41^{\circ} \mathrm{C}\right)$, they concluded that with increasing temperature, the membrane average pore size increased (12\% for the TFC-S and $21 \%$ in the case of the DL) and the pore density decreased because of the thermal expansion of the polymer constituting the active layer of these membranes. Amar et al. [27] used four uncharged solutes (i.e. sucrose, glucose, arabinose and glycerine) to characterize the pore size of the NF membrane Desal 5DK based on the same solute transport model. They reported that when the temperature increased from 22 to $40{ }^{\circ} \mathrm{C}$, the average pore radius of Desal 5DK increased approximately $9 \%$. It is noteworthy that as the feed solution temperature increased, the membrane permeability increased (data not reported) which has been attributed the decrease in water viscosity. However, results from Table 3 indicate that the increase in membrane pore size can also be a major factor for permeability increase at high feed solution temperature.

It is apparent that the feed temperature has a significant influence on the pore radius of the membrane which can subsequently impact the rejection of TrOCs. Therefore, a systematic investigation of the rejection behaviour of the selected TrOCs under different temperature conditions will be explored in the next section.

\subsection{Effect of temperature on TrOC rejection}

Changes in solute rejection in response to the increase in membrane pore size (due to increasing feed solution temperature) were simulated by taking into account the influence of temperature on the solute diffusion coefficient Eq. (7). The data presented in Fig. 2 were obtained based on the assumption that the solute is spherical and steric hindrance is the only rejection mechanism. Data presented in Fig. 2 demonstrate that the impact of solution temperature on membrane pore size can subsequently exert a considerable influence on solute rejection. The results also suggest that the impact of solution temperature on rejection is more severe for solutes that are moderately rejected by the membrane. Indeed, the impacts of solution temperature on large solutes (that are completely rejected) and small solutes (that are poorly rejected) appear to be negligible (Fig. 2).

[Figure 2]

Experimental data showing the impact of feed temperature increase on TrOC rejection are presented in Figs. 3 and 4. In good agreement with the simulated data in Fig. 2, the rejection all 
selected TrOCs decreased as the solution temperature increase (which led to an increase in membrane pore size as reported in Table 3). Additionally, as shown in Table 1, with increasing temperature from 20 to $40{ }^{\circ} \mathrm{C}$, diffusion coefficient of all the examined TrOCs increased significantly. Therefore during NF separation, the increase in diffusion of these compounds across the membrane could also results in lower observed rejection values at higher temperature. These results and interpretation are consistent with the previous observations in the literature [29-31].

\section{[Figure 3]}

\section{[Figure 4]}

There are notable differences in rejection efficiencies as well as the decrease in rejection with increasing temperature of both the negatively charged and neutral TrOCs. At a given temperature, rejection of the negatively charged TrOCs decreased as their molecular width decreased (Table 1 and Fig. 3). This is consistent with results previously reported in other investigations [4, 32]. However, temperature has only marginal impact on the rejection of TrOCs (i.e. bezafibrate, sulfamethoxazole, trimethoprim, and diclofenac) that are well rejected by the NF270 membrane (Fig. 3). Because the NF270 membrane is negatively charged, rejection of negatively charged solution is governed by charge repulsion. Thus, the increase in membrane pore size could not exert any significant impact on the rejection of these TrOCs. On the other hand, the feed solution temperature exerted a significant impact on the rejection of the other three negatively charged TrOCs (i.e. formononetin, genistein and pentachlorophenol) which were only moderately rejected by the NF270 membrane at the lowest temperature (i.e. $20^{\circ} \mathrm{C}$ ) studied here (Fig. 3). The molecular widths of these TrOCs are from 0.354 to 0.412 , which is smaller than the estimated membrane pore size (Table 3). Thus, the increase in membrane pore size and solute diffusion coefficient can play a major role in the decrease of their rejection as the solution temperature increases.

The rejection of neutral TrOCs is governed mostly by size exclusion. As a result, notable impact of feed solution temperature on the rejection of all neutral TrOCs was observed (Fig. 4). Of these neutral TrOCs, amitriptyline and linuron are hydrophobic $(\log \mathrm{D}>3)$. Thus, notable adsorption of these TrOCs to the membrane could be observed based on a mass balance calculation (data not shown). More importantly, the impact of solution temperature on their rejection is more significant than other TrOCs with similar rejection values at $20^{\circ} \mathrm{C}$.

\section{Conclusions}

The results showed that the feed temperature had a significant impact on the NF270 membrane pore radius. When the temperature increased from 20 to $40{ }^{\circ} \mathrm{C}$, the average pore radius of the membrane (obtained from three reference organic solutes) increased from 0.39 to $0.44 \mathrm{~nm}$, as 
determined by using uncharged reference solutes and a simple pore-hindrance model. This has been adequately explained by the thermal expansion of the polymer constituting the active layer of thin film composite membrane, leading to the alterations in the pore structure of the membrane with the increasing temperature. The results also show that an increase feed solution temperature could adversely influence the rejection of TrOCs. The impact of feed solution temperature on TrOC rejection could be attributed to the combined effects of the increase in membrane pore size and solute diffusion coefficient. In addition, the differences in magnitude of the impact of temperature on TrOC rejection can be explained by their rejection mechanisms. The impact of feed temperature on the rejection of neutral TrOCs was more pronounced compared to the negatively charged TrOCs. This is because both charge repulsion and size exclusion are responsible for the rejection of these negatively charged TrOCs. Charge repulsion is, however, not influenced by changes in the membrane pore size. Furthermore, the rejection of neutral and hydrophobic TrOCs appears to be most influenced by changes in the feed solution temperature.

\section{Acknowledgements}

The authors acknowledge the support of the Ministry of Agriculture and Rural Development of Vietnam (MARD), and the University of Wollongong for a doctoral scholarship, and a Viet Mard top-up Award to Hai Quang Dang.

\section{References}

[1] C. Bellona and J.E. Drewes, Viability of a low-pressure nanofilter in treating recycled water for water reuse applications: A pilot-scale study. Water Res., 41 (2007): p. 3948-3958.

[2] K. Kimura, S. Toshima, G. Amy, and Y. Watanabe, Rejection of neutral endocrine disrupting compounds (EDCs) and pharmaceutical active compounds (PhACs) by RO membranes. $J$. Membr. Sci., 245 (2004): p. 71-78.

[3] L.D. Nghiem, A.I. Schäfer, and M. Elimelech, Removal of Natural Hormones by Nanofiltration Membranes: Measurement, Modeling, and Mechanisms. Environ. Sci. Technol., 38(6) (2004): p. 1888-1896.

[4] V. Yangali-Quintanilla, A. Sadmani, M. McConville, M. Kennedy, and G. Amy, Rejection of pharmaceutically active compounds and endocrine disrupting compounds by clean and fouled nanofiltration membranes. Water Res., 43 (2009): p. 2349-2362.

[5] A.M. Comerton, R.C. Andrews, D.M. Bagley, and C. Hao, The rejection of endocrine disrupting and pharmaceutically active compounds by NF and RO membranes as a function of compound and water matrix properties. J. Membr. Sci., 313(1-2) (2008): p. 323-335.

[6] J.H. Al-Rifai, H. Khabbaz, and A.I. Schäfer, Removal of pharmaceuticals and endocrine disrupting compounds in a water recycling process using reverse osmosis systems. Sep. Purif. Technol., 77 (2011): p. 60-67.

[7] L.D. Nghiem and A.I. Schafer, Critical risk points of nanofiltration and reverse osmosis processes in water recycling applications. Desalination, 187(1-3) (2006): p. 303-312.

[8] M.F.A. Goosen, S.S. Sablani, S.S. Al-Maskari, R.H. Al-Belushi, and M. Wilf, Effect of feed temperature on permeate flux and mass transfer coefficient in spiral-wound reverse osmosis systems. Desalination, 144 (2002): p. 367-372. 
[9] J. Schaep, B. Van der Bruggen, S. Uytterhoeven, R. Croux, C. Vandecasteele, D. Wilms, E. Van Houtte, and F. Vanlerberghe, Removal of hardness from groundwater by nanofiltration. Desalination, 119(1-3) (1998): p. 295-302.

[10] X. Jian, Y. Dai, G. He, and G. Chen, Preparation of UF and NF poly (phthalazine ether sulfone ketone) membranes for high temperature application. J. Membr. Sci., 161(1-2) (1999): p. 185191.

[11] R.R. Sharma, R. Agrawal, and S. Chellam, Temperature effects on sieving characteristics of thin-film composite nanofiltration membranes: pore size distributions and transport parameters. J. Membr. Sci., 223 (2003): p. 69-87.

[12] W.R. Bowen, A.W. Mohammad, and N. Hilai, Characterisation of nanofiltration membranes for predictive purposes - use of salts, uncharged solutes and atomic force microscopy. $J$. Membr. Sci., 126 (1997): p. 91-105.

[13] X.L. Wang, T. Tsuru, S. Nakao, and S. Kimura, The electrostatic and steric-hindrance model for the transport of charged solutes through nanofiltration membranes. J. Membr. Sci., 135(1) (1997): p. 19-32.

[14] W.R. Bowen and J.S. Welfoot, Modelling the performance of membrane nanofiltration critical assessment and model development. Chem. Eng. Sci., 57(7) (2002): p. 1121-1137.

[15] M.J. López-Muňoz, A. Sotto, J.M. Arsuaga, and B. Van der Bruggen, Influence of membrane, solute and solution properties on the retention of phenolic compounds in aqueous solution by nanofiltration membranes. Sep. Purif. Technol., 66(1) (2009): p. 194-201.

[16] L.D. Nghiem, A.I. Schäfer, and M. Elimelech, Pharmaceutical Retention Mechanisms by Nanofiltration Membranes. Environ. Sci. Technol., 39(19) (2005): p. 7698-7705.

[17] J.G. Aleman and J.M. Dickson, Mathematical modeling of nanofiltration membranes with mixed electrolyte solutions. J. Membr. Sci., 235 (2004): p. 1-13.

[18] Y. Kiso, K. Muroshige, T. Oguchi, T. Yamada, M. Hhirose, T. Ohara, and T. Shintani, Effect of molecular shape on rejection of uncharged organic compounds by nanofiltration membranes and on calculated pore radii. J. Membr. Sci., 358(1-2) (2010): p. 101-113.

[19] R.K. Sinnott, Chemical Engineering Design. Fourth ed. Vol. 6. 2005, Elsevier ButterworthHeinemann, Linacre House, Jordan Hill, Oxford OX2 8DP, England. 1038.

[20] A.R.D. Verliefde, E.R. Cornelissen, S.G.J. Heijman, J.Q.J.C. Verberk, G.L. Amy, B. Van der Bruggen, and J.C. van Dijk, Construction and validation of a full-scale model for rejection of organic micropollutants by NF membranes. J. Membr. Sci., 339(1-2) (2009): p. 10-20.

[21] W.R. Bowen, J.S. Welfoot, and P.M. Williams, Linearized Transport Model for Nanofiltration:Development and Assessment. AlChE J., 48(4) (2002): p. 760-773.

[22] J.L.C. Santos, P.D. Beukelaar, I.F.J. Vankelecom, S. Velizarov, and J.G. Crespo, Effect of solute geometry and orientation on the rejection of uncharged compounds by nanofiltration. Sep. Purif. Technol., 50 (2006): p. 122-131.

[23] A.L. Ahmad, L.S. Tan, and S.R.A. Shukor, Modeling of the retention of atrazine and dimethoate with nanofiltration. Chem. Eng. J., 147 (2009): p. 280-286.

[24] E.R. Cornelissen, J. Verdouw, A.J. Gijsbertsen-Abrahamse, and J.A.M.H. Hofman, A nanofiltration retention model for trace contaminants in drinking water sources. Desalination, 178 (2005): p. 179-192.

[25] J. Kang, W.E. Price, and L.A. Hick, Simultaneous determination of isoflavones and lignans at trace levels in natural waters and wastewater samples using liquid chromatography/electrospray ionization ion trap mass spectrometry. Rapid Commun. Mass Spectrom., 20(16) (2006): p. 2411-2418.

[26] M. Xie, W.E. Price, L.D. Nghiem, and M. Elimelech, Effects of feed and draw solution temperature and transmembrane temperature difference on the rejection of trace organic contaminants by forward osmosis. J. Membr. Sci., 438(0) (2013): p. 57-64.

[27] N.B. Amar, H. Saidani, A. Deratani, and J. Palmeri, Effect of Temperature on the Transport of Water and Neutral Solutes across Nanofiltration Membranes. Langmuir, 23 (2007): p. 29372952. 
[28] R.R. Sharma and S. Chellam, Temperature Effects on the Morphology of Porous Thin Film Composite Nanofiltration Membranes. Environ. Sci. Technol., 39(13) (2005): p. 5022-5030.

[29] T. Tsuru, S. Izumi, T. Yoshioka, and M. Asaeda, Temperature Effect on Transport Performance by Inorganic Nanofiltration Membranes. AlChE J., 46(3) (2000): p. 565-574.

[30] N.B. Amar, H. Saidani, J. Palmeri, and A. Deratani, Effect of temperature on the rejection of neutral and charged solutes by Desal 5 DK nanofiltration membrane. Desalination, 246 (2009): p. 294-303.

[31] T. Fujioka, L.D. Nghiem, S.J. Khan, J.A. McDonald, Y. Poussade, and J.E. Drewes, Effects of feed solution characteristics on the rejection of $\mathrm{N}$-nitrosamines by reverse osmosis membranes. J. Membr. Sci., 409-410 (2012): p. 66-74.

[32] K.O. Agenson, J.I. Oh, and T. Urase, Retention of a wide variety of organic pollutants by different nanofiltration/reverse osmosis membranes: controlling parameters of process. $J$. Membr. Sci., 225 (2003): p. 91-103. 


\section{Figure captions}

Fig. 1. Real rejection of (a) erythritol, (b) xylose and (c) glucose by the NF270 membrane as a function of permeate flux at 20,30 and $40{ }^{\circ} \mathrm{C}$. The error bars represent standard deviation of data obtained from two independent experiments.

Fig. 2. Changes in real rejection of idealised spherical solutes as a function of membrane pore radius (due to feed temperature increases from 20 to $40^{\circ} \mathrm{C}$ ).

Fig. 3. Rejection of the negatively charged TrOCs by the NF270 membrane as a function of feed temperature. The error bars represent standard deviation of four measurements of rejection efficiency in two repeated experiments.

Fig. 4. Rejection of the neutral TrOCs by the NF270 membrane as a function of feed temperature. The error bars represent standard deviation of four measurements of rejection efficiency in two repeated experiments. 

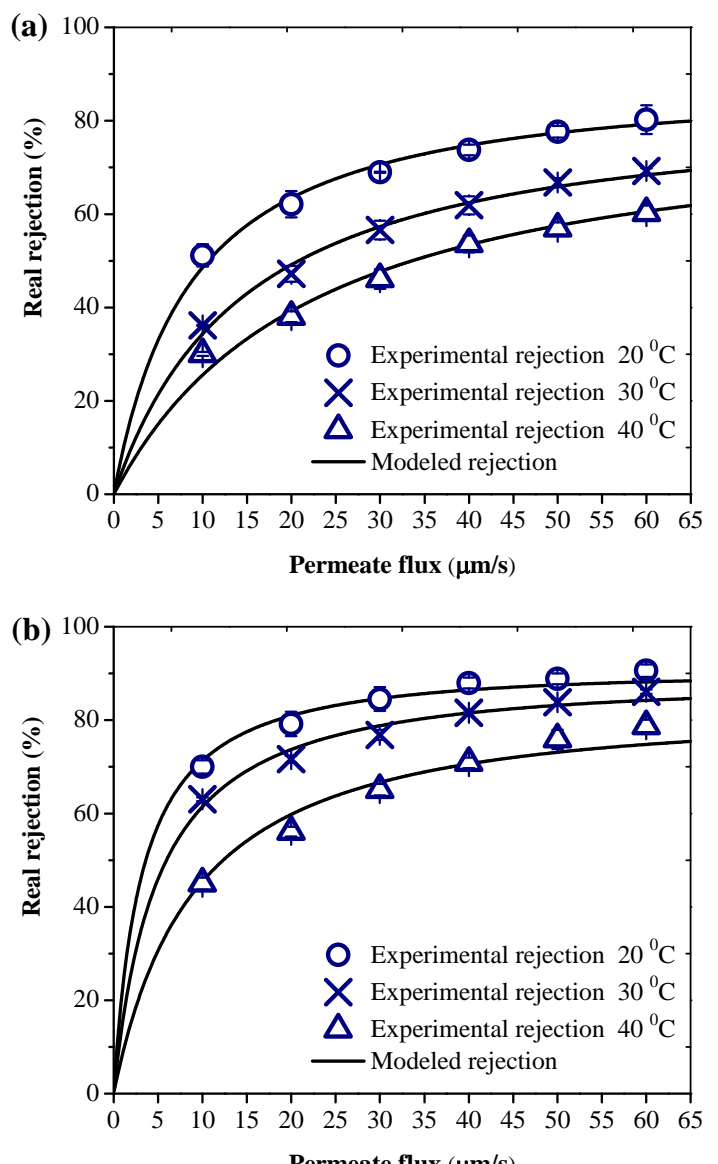

Permeate flux $(\mu \mathrm{m} / \mathrm{s})$

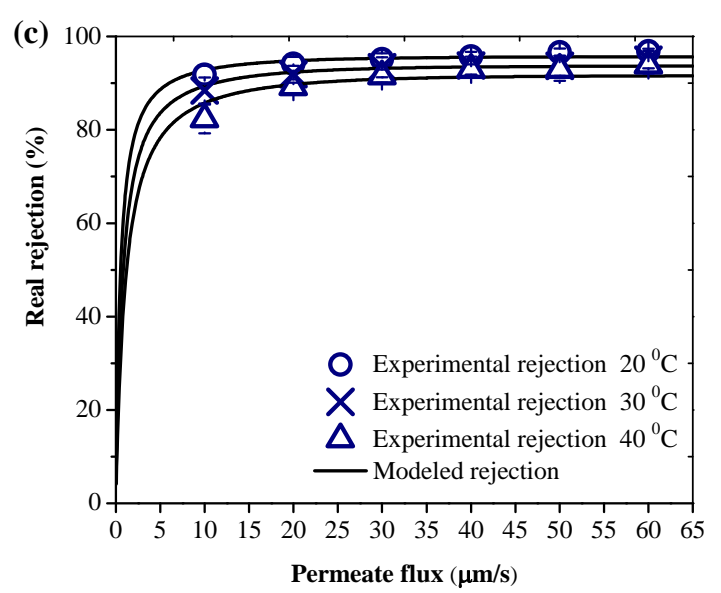

Fig. 1. 


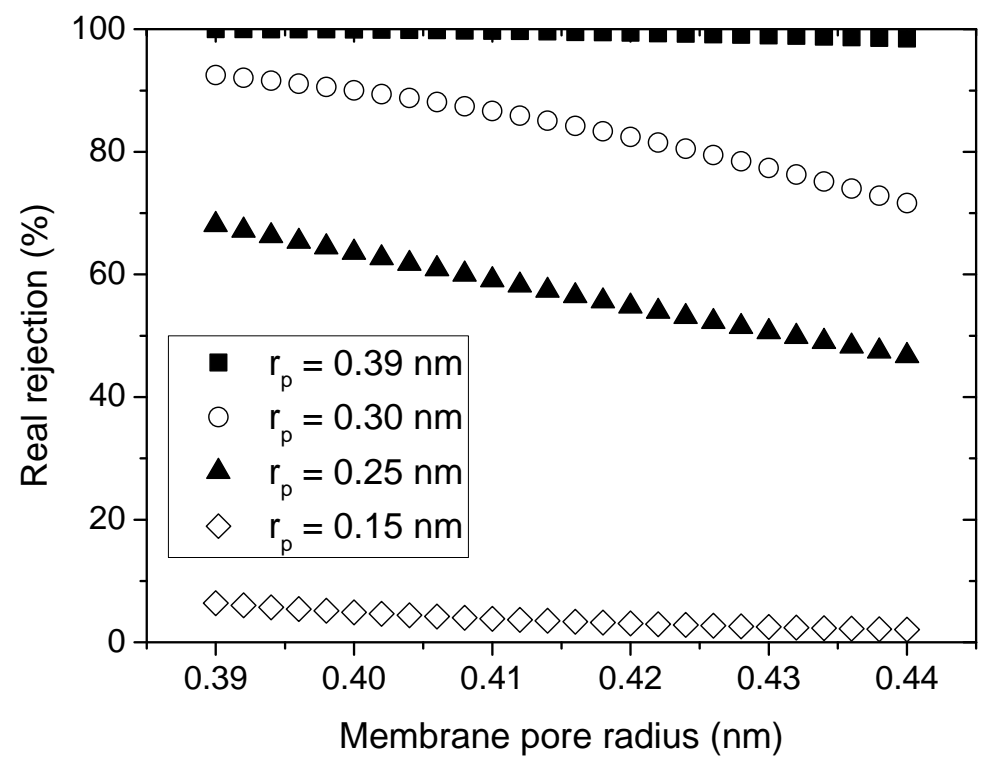

Fig. 2. 

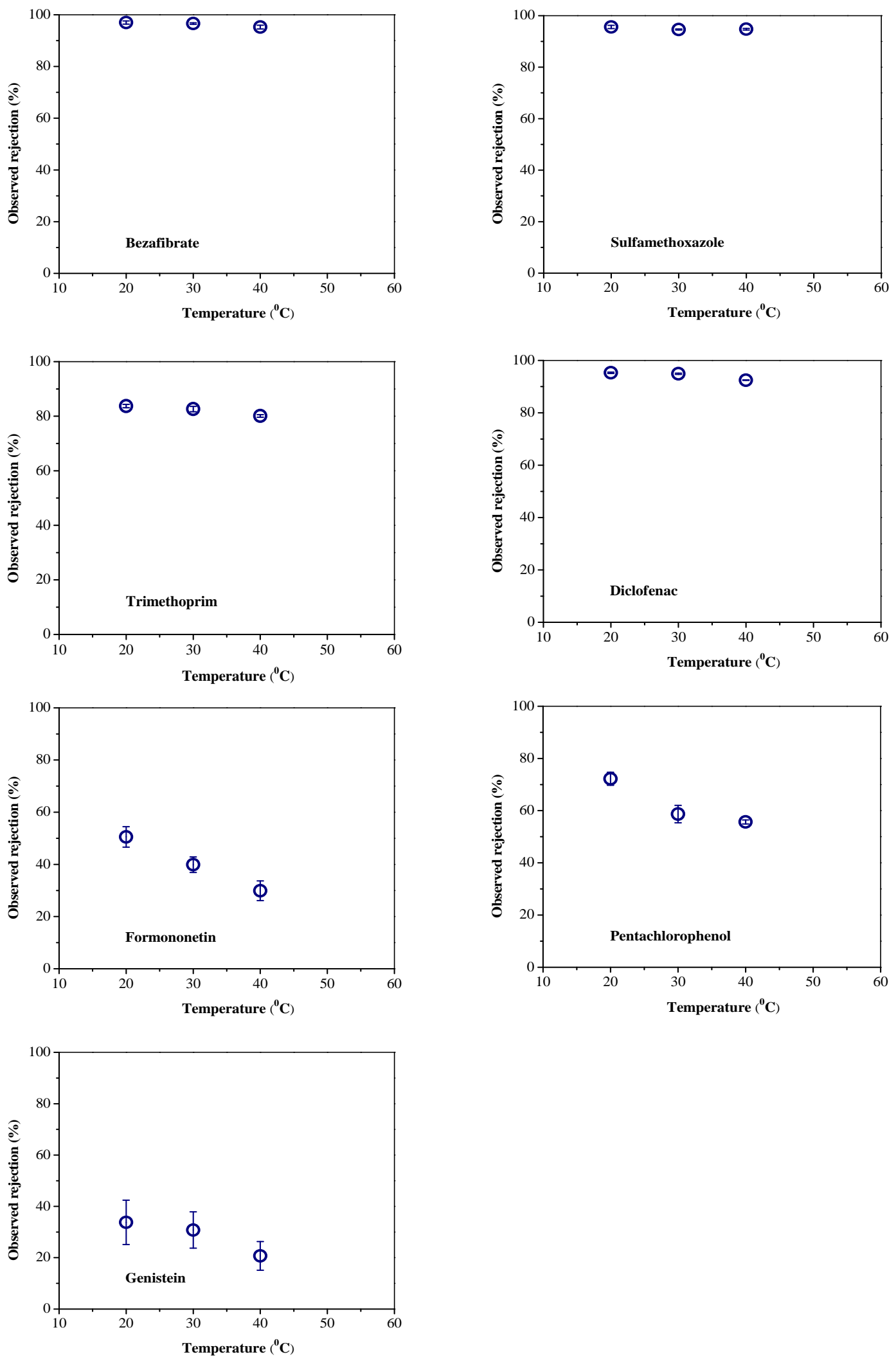

Fig. 3. 

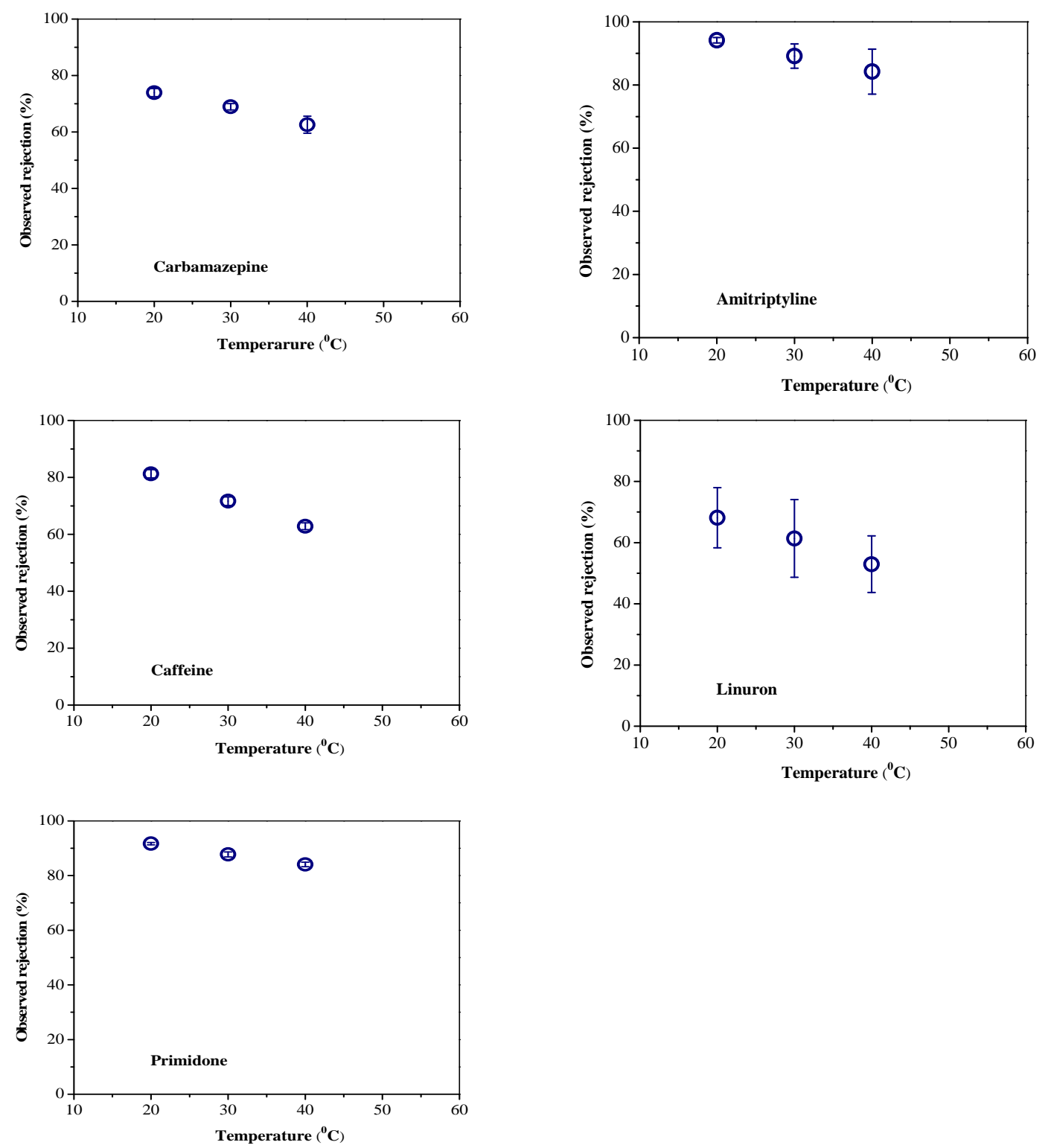

Fig. 4. 
Table 1

Physicochemical properties of the selected TrOCs.

\begin{tabular}{|c|c|c|c|c|c|c|c|c|c|}
\hline \multirow[t]{2}{*}{ Compound } & \multirow[t]{2}{*}{ Molecular structure } & \multirow{2}{*}{$\begin{array}{l}\text { Molecular } \\
\text { weight } \\
(\mathrm{g} / \mathrm{mol})\end{array}$} & \multirow{2}{*}{$\begin{array}{l}\text { Molecular } \\
\text { width }^{\mathrm{a}}(\mathrm{nm})\end{array}$} & \multirow[t]{2}{*}{$\mathrm{pK}_{\mathrm{a}}{ }^{\mathrm{b}}$} & \multirow{2}{*}{$\begin{array}{l}\text { Charge at } \\
\mathrm{pH} 8\end{array}$} & \multirow{2}{*}{$\begin{array}{l}\text { Log D at } \\
\mathrm{pH} 8^{\mathrm{b}}\end{array}$} & \multicolumn{3}{|c|}{ Diffusion coefficient ${ }^{\mathrm{c}}, \mathrm{D}\left(10^{-10} \mathrm{~m}^{2} / \mathrm{s}\right)$} \\
\hline & & & & & & & $20^{\circ} \mathrm{C}$ & $30^{\circ} \mathrm{C}$ & $40^{\circ} \mathrm{C}$ \\
\hline Bezafibrate & & 362 & 0.420 & 3.29 & Negative & -1.20 & 4.06 & 5.27 & 6.65 \\
\hline Sulfamethoxazole & & 253 & 0.412 & 5.81 & Negative & -0.96 & 5.38 & 6.99 & 8.82 \\
\hline Trimethoprim & & 290 & 0.420 & 7.04 & Negative & 0.55 & 4.60 & 5.97 & 7.54 \\
\hline Diclofenac & & 296 & 0.354 & 4.18 & Negative & 1.06 & 4.86 & 6.31 & 7.97 \\
\hline Formononetin & & 268 & 0.412 & 6.99 & Negative & 1.81 & 5.11 & 6.64 & 8.38 \\
\hline Genistein & & 270 & 0.354 & 6.51 & Negative & 1.14 & 5.33 & 6.92 & 8.74 \\
\hline Pentachlorophenol & & 266 & 0.354 & 4.68 & Negative & 2.19 & 6.30 & 8.18 & 10.32 \\
\hline
\end{tabular}




\begin{tabular}{|c|c|c|c|c|c|c|c|c|c|}
\hline \multirow[t]{2}{*}{ Compound } & \multirow[t]{2}{*}{ Molecular structure } & \multirow{2}{*}{$\begin{array}{l}\text { Molecular } \\
\text { weight } \\
(\mathrm{g} / \mathrm{mol})\end{array}$} & \multirow{2}{*}{$\begin{array}{l}\text { Molecular } \\
\text { width }^{\mathrm{a}}(\mathrm{nm})\end{array}$} & \multirow[t]{2}{*}{$\mathrm{pK}_{\mathrm{a}}{ }^{\mathrm{b}}$} & \multirow{2}{*}{$\begin{array}{l}\text { Charge at } \\
\mathrm{pH} 8\end{array}$} & \multirow{2}{*}{$\begin{array}{l}\text { Log D at } \\
\mathrm{pH}^{\mathrm{b}}\end{array}$} & \multicolumn{3}{|c|}{ Diffusion coefficient ${ }^{\mathrm{c}}, \mathrm{D}\left(10^{-10} \mathrm{~m}^{2} / \mathrm{s}\right)$} \\
\hline & & & & & & & $20^{\circ} \mathrm{C}$ & $30^{\circ} \mathrm{C}$ & $40^{\circ} \mathrm{C}$ \\
\hline Carbamazepine & & 236 & 0.354 & 13.94 & Neutral & 1.89 & 5.43 & 7.05 & 8.89 \\
\hline Primidone & & 218 & 0.426 & 12.26 & Neutral & 0.83 & 5.55 & 7.21 & 9.10 \\
\hline Caffeine & & 194 & 0.412 & 0.52 & Neutral & -0.63 & 6.32 & 8.21 & 10.36 \\
\hline Amitriptyline & & 277 & 0.435 & 9.18 & Neutral & 3.21 & 4.45 & 5.78 & 7.29 \\
\hline Linuron & & 249 & 0.412 & 12.13 & Neutral & 3.12 & 5.57 & 7.23 & 9.13 \\
\hline
\end{tabular}

${ }^{\mathrm{a}}$ Calculated using Molecular Modeling Pro ${ }^{\mathrm{TM}}$ Plus software; ${ }^{\mathrm{b}}$ Scifinder Scholar; ${ }^{\mathrm{c}}$ Calculated using Eq. (7). 
Table 2

Molecular weight, Stokes radius and transport parameters of reference organic compounds.

\begin{tabular}{|c|c|c|c|c|}
\hline Organic compound & & Erythritol & Xylose & Glucose \\
\hline Molecular weight (g/mol) & & 122 & 150 & 180 \\
\hline Stokes radius, $\mathrm{r}_{\mathrm{s}}(\mathrm{nm})^{\mathrm{a}}$ & & 0.26 & 0.28 & 0.31 \\
\hline \multirow{3}{*}{ Diffusion coefficient, $D\left(10^{-10} \mathrm{~m}^{2} / \mathrm{s}\right)^{b}$} & $20^{\circ} \mathrm{C}$ & 8.14 & 7.75 & 6.89 \\
\hline & $30^{\circ} \mathrm{C}$ & 10.57 & 10.06 & 8.94 \\
\hline & $40^{\circ} \mathrm{C}$ & 13.34 & 12.70 & 11.29 \\
\hline \multirow{3}{*}{ Mass transfer coefficient, $\mathrm{k}_{\mathrm{f}}\left(10^{-5} \mathrm{~m} / \mathrm{s}\right)^{\mathrm{c}}$} & $20^{\circ} \mathrm{C}$ & 4.03 & 3.88 & 3.55 \\
\hline & $30^{\circ} \mathrm{C}$ & 5.65 & 5.44 & 4.98 \\
\hline & $40^{\circ} \mathrm{C}$ & 7.60 & 7.33 & 6.71 \\
\hline
\end{tabular}

a, b, c Calculated using Eqs. (8), (7) and (16), respectively.

Table 3

Average pore radius of the NF270 membrane obtained from reference organic compounds at 20,30 and $40{ }^{\circ} \mathrm{C}$.

\begin{tabular}{lllllll}
\hline \multirow{2}{*}{$\begin{array}{l}\text { Organic } \\
\text { compound }\end{array}$} & \multicolumn{2}{c}{$20^{\circ} \mathrm{C}$} & \multicolumn{3}{c}{$30^{\circ} \mathrm{C}$} & \multicolumn{2}{c}{$40^{\circ} \mathrm{C}$} \\
\cline { 2 - 7 } & $\lambda=\mathrm{r}_{\mathrm{s}} / \mathrm{r}_{\mathrm{p}}$ & $\mathrm{r}_{\mathrm{p}}(\mathrm{nm})$ & $\lambda=\mathrm{r}_{\mathrm{s}} / \mathrm{r}_{\mathrm{p}}$ & $\mathrm{r}_{\mathrm{p}}(\mathrm{nm})$ & $\lambda=\mathrm{r}_{\mathrm{s}} / \mathrm{r}_{\mathrm{p}}$ & $\mathrm{r}_{\mathrm{p}}(\mathrm{nm})$ \\
\hline Erythritol & 0.67 & 0.39 & 0.60 & 0.43 & 0.58 & 0.45 \\
Xylose & 0.72 & 0.39 & 0.69 & 0.41 & 0.62 & 0.45 \\
Glucose & 0.80 & 0.39 & 0.77 & 0.40 & 0.74 & 0.42 \\
Average & & $0.39 \pm 0.00$ & & $0.41 \pm 0.02$ & & $0.44 \pm 0.02$ \\
\hline
\end{tabular}

